\title{
A Review of the Diamond Retention Capacity of Metal Bond Matrices
}

\author{
Xiaojun Zhao (i) and Longchen Duan* \\ Faculty of Engineering, China University of Geosciences, Wuhan 430074, China; zhaoxiaojun@cug.edu.cn \\ * Correspondence: duanlongchen@163.com; Tel.: +86-138-8608-1092
}

Received: 30 March 2018; Accepted: 27 April 2018; Published: 29 April 2018

\begin{abstract}
This article presents a review of the current research into the diamond retention capacity of metal matrices, which largely determines the service life and working performance of diamond tools. The constitution of diamond retention capacity, including physical adsorption force, mechanical inlaying force, and chemical bonding force, are described. Improved techniques are summarized as three major types: (1) surface treatment of the diamond: metallization and roughening of the diamond surface; (2) modification of metal matrix: the addition of strong carbide forming elements, rare earth elements and some non-metallic elements, and pre-alloying or refining of matrix powders; (3) change in preparation technology: the adjustment of the sintering process and the application of new technologies. Additionally, the methods used in the evaluation of diamond retention strength are introduced, including three categories: (1) instrument detection methods: scanning electron microscopy, X-ray diffractometry, energy dispersive spectrometry and Raman spectroscopy; (2) mechanical test methods: bending strength analytical method, tension ring test method, and other test methods for chemical bonding strength; (3) mechanical calculation methods: theoretical calculation and numerical computation. Finally, future research directions are discussed.
\end{abstract}

Keywords: diamond retention capacity; holding strength; bonding strength; metal matrix; improved techniques; evaluation methods

\section{Introduction}

Diamond tools are widely used for cutting, grinding, sawing, drilling, and polishing hard materials, such as stone, concrete, cemented carbides, optical glass, advanced ceramics, and other difficult-to-process materials [1-3]. This is due to diamond's unique physicochemical characteristics, namely its extreme hardness and high strength, as well as its good abrasion resistance and low thermal expansion [4]. Most diamond tools are in the form of a composite structure with diamond grits embedded in a bonding matrix. The most common diamond tools can be divided into three classes, namely metallic, vitrified and resinous, according to the bonding agent used [5]. Among these three categories of diamond tools, metal-bonded diamond tools are the most widely used because of the high bonding strength, good formability and long service life, especially in processing hard and brittle material [6].

The production process of metal-bonded diamond tools involves mixing metal powders with synthetic or natural diamond particles, and then sintering or hot pressing the mixtures $[7,8]$. The sintered diamond compact is generally made up of two parts: diamond and matrix. The diamond is the cutting element and the most basic component, and the matrix has a determinative effect on whether or not the diamond can function fully and effectively [9]. There are two basic functions required in the metal matrix [10]. First, the matrix needs to wear at a rate compatible comparable to that of the diamond—due to their self-sharpening ability, worn diamonds fall out to allow new diamonds 
to continuously be exposed [4,11]. The second and equally important function of the matrix is to hold the diamonds firmly in place to avoid them falling-out too early [12]. The diamond retention capacity of a metal-bond matrix largely determines the diamond tool's service life and working performance. This article presents a review on the current research into the holding capacity of metal matrices in diamond tool technology.

\section{Constitution of Diamond Retention Capacity}

The term 'diamond retention' denotes the capacity of a metallic matrix material to retain diamond particles at the surface [13]. Diamond retention capacity can be explained by physical adsorption, mechanical inlay, and chemical bonding at the interface between the diamond and the surrounding matrix $[14,15]$. The physical adsorption force is a kind of intermolecular force, including the van der Waals force and hydrogen bond force, and while ubiquitous, it is too weak to bond the diamond with the matrix, so can be neglected in general cases.

The mechanical inlaying force comes from mechanical interlocking between the matrix and diamond grains. The matrix plays a support role for the diamond grains through adhesion and friction [16], and the diamond grains are compressed by the shrinking matrix during the cooling stage upon sintering. Compressive stress arises from differences in the thermal expansion coefficient between the diamond and the matrix, augmented by any volume changes due to cooling contraction or phase transition [13]. The thermal expansion mismatch between diamonds and the metal matrix induces residual stress at the interface, which is responsible for the mechanical retention capability [5]. The efficiency of the mechanical bonding depends on the porosity, the sintering alloying degree, the thermal coefficient of expansion, and the mechanical properties of the matrix. The mechanical retention ability is limited by the yield strength of the matrix, and can only provide low interfacial strength [17].

The chemical bonding force derives from the chemical reaction at the interface of the matrix and diamonds under certain pressure and temperature conditions during the sintering process. The existence of this chemical reaction depends on the composition of the metal powder, its particle size and distribution, oxidation and/or reducing gases, and the temperature and duration of the sintering process [18]. The chemical bonding force is an interatomic action force which consists of metallic, ionic and covalent bonds, and its strength depends on the bond types and the number of bonds over the unit area. Additionally, the chemical retention capacity is generally as high as several hundred megapascals, and forms strong interfacial bonding to improve the efficiency of diamonds [19].

Theoretically speaking, the capacity of the chemical bonding is much larger than that of the mechanical retention, but it is very difficult to produce chemical bonding between diamonds and the metal binding agent. This is due to the fact that diamond is relatively chemically inert, and has high interfacial energy with metallic surfaces [20], resulting in difficulty chemically reacting metals in the binder with the diamonds, or infiltrating the diamond surfaces. Consequently, the diamond retention capacity mainly depends on the mechanical inlaying force for general metal-bonded diamond tools, causing a weak bonding strength between diamonds and matrix [21]. For this reason, the diamond grains easily fall out of the matrix in the working process, which ultimately reduces the utilization and service life of diamond tools [22].

\section{Improved Techniques of Diamond Retention Capacity}

According to the previous research results, the key to enhancing diamond retention capacity is to improve the interfacial bonding state between the matrix and diamonds. These specific enhanced measures are summarized as three major types: surface treatment of the diamond, modification of the metal matrix, and change in preparation technology. 


\subsection{Surface Treatment of Diamond}

As a consequence of the chemical reactivity of the metal matrix composites, three different bonding behaviors between diamond and metal were observed in previous investigations [23,24]: (1) diamond degradation and graphite formation: elements with a catalytic effect on carbon lead to graphitization and diamond degradation occurs. The diamond retention capacity is weak due to the graphite layer on the diamond surface; (2) carbide formation: a generated carbide epitaxially grows on diamond surfaces and causes strong bonding between carbon and metal; (3) inert behavior: when no chemical reactions or diffusion process occur, inert behavior takes place, and the diamonds are only mechanically bonded within the metal matrix.

It is therefore expected that the diamond retention is strengthened through diamond surface metallization by coating with strong carbide-forming elements (Mo, Ti, V, W, Cr, etc.) prior to blending with the metal matrix powders [25-27]. Metallization of the diamond surface has some basic and important roles. The first is to improve diamond retention strength through reducing the interface energy between diamond grits and the metal matrix, increasing the diamond surface roughness, and the relaxation of residual stress with a coated interlayer [28-30]. The second role is to protect the diamond surface, preventing oxidization and graphitization of the diamond under high temperatures, because the coatings avoid the immediate contact between the diamond and oxygen, and catalytic elements such as iron, nickel and cobalt [31-33]. The coatings also fill the micro pores and cracks in the diamond surfaces, and in doing so, can bridge surface defects and enhance the strength of the diamond grits [34]. Figure 1 shows the interfacial morphology around tungsten-coated diamond is more desirable, which exhibits fewer cracks [35].

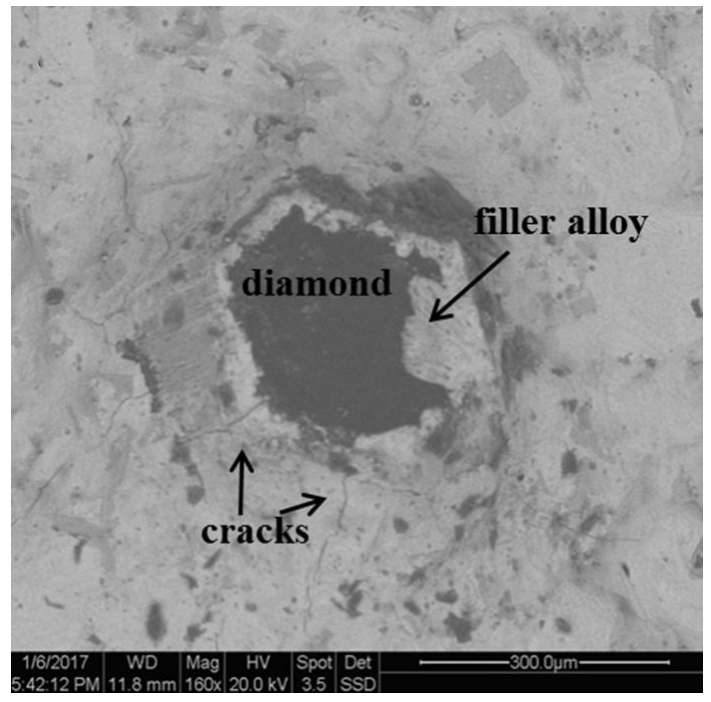

(a)

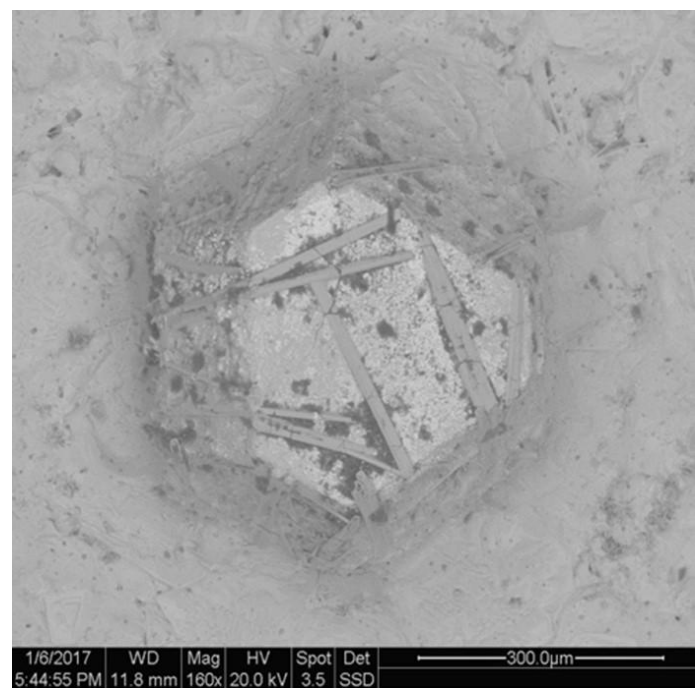

(b)

Figure 1. SEM images of diamond-matrix interface: (a) uncoated diamond, (b) tungsten-coated diamond [35], Taylor \& Francis, 2018.

The theory of diamond surface metallization is based on the formation of a carbide layer due to the intense interfacial chemical reaction between diamond and strong carbide-forming elements under the appropriate process conditions. According to the model of diamond surface metallization (see Figure 2), the coated layer at the surface can be divided into three layers: from inside and out, carbide, alloy, and a metal surface layer. The coated layer can bond the diamond surface as it generates a corresponding carbide, while its outside surface layer forms a braze weld with the metal bonding agent during the sintering process. As a result, the intermediary role of the coated layer creates the strong bonding between diamond and matrix. Many methods are used to achieve diamond surface 
metallization, such as physical vapor deposition, chemical vapor deposition, vacuum slowly vapor deposition, molten salt method, magnetron sputtering, and laser cladding [22].

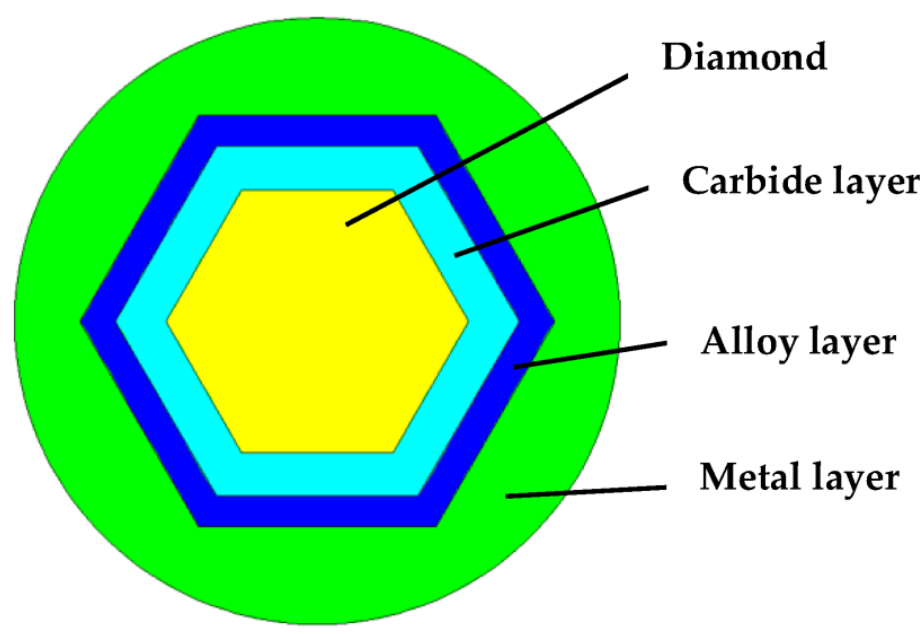

Figure 2. Model diagram of diamond surface metallization.

Except for surface metallization of diamond, the surface roughening method is also employed to improve diamond retention [36]. The method generates tiny concave pits and cracks on the diamond surface which increases surface roughness, thereby strengthening the mechanical interlocking effect which is responsible for the enhancement on the mechanical retention capability [37]. The surface roughening method can be either strong or weak. The strong roughening method generates diamond graphitization by making use of molten chloride-based salt to erode the diamond surface, while in the weak roughening method, slight graphitization occurs on the diamond surface, due to the strong oxidation and corrosion of acid.

However, the surface roughening method has an essential disadvantage in that a relatively large quantity of material must be removed from the diamond surface before its topography guarantees satisfactory improvement in the bonding strength. There is also a considerable risk that such surface etching may harm the diamond's integrity and strength [12]. Therefore, this method has not found widespread application.

\subsection{Modification of Metal Matrix}

Modification of the metal matrix by changing the material composition reduces the surface energy and improves bonding between the matrix and diamonds. The modification methods mainly include the addition of strong carbide forming elements, rare earth elements, non-metallic elements, and the pre-alloying or refining of matrix powders.

\subsubsection{Strong Carbide Forming Elements}

Similar to diamond surface metallization, the strong carbide forming elements added in matrix powders can also form a transition carbide layer between the bonding matrix and the diamond grits during the process of heat treatment or sintering [38,39], thereby combining the diamond grits with the metal matrix metallurgically [22]. Away from this interfacial layer, various intermetallic compounds precipitate in the bonding matrix, further alleviating the interfacial stress associated with a mismatch in the thermal expansion coefficient and phase transformation during cooling [40]. Furthermore, the additives of strong carbide forming elements have solid solution strengthening effects on the metal matrix [41]. According to [42], the strong carbide forming element $V$ can promote the metallurgical reaction between matrix and diamond, which gathered in the surface of diamond. Figure 3 shows that 
the flexural strength and the holding force increase with the increasing content of $\mathrm{V}$, when the content of element $\mathrm{V}$ is lower than $4 \%$ [42].

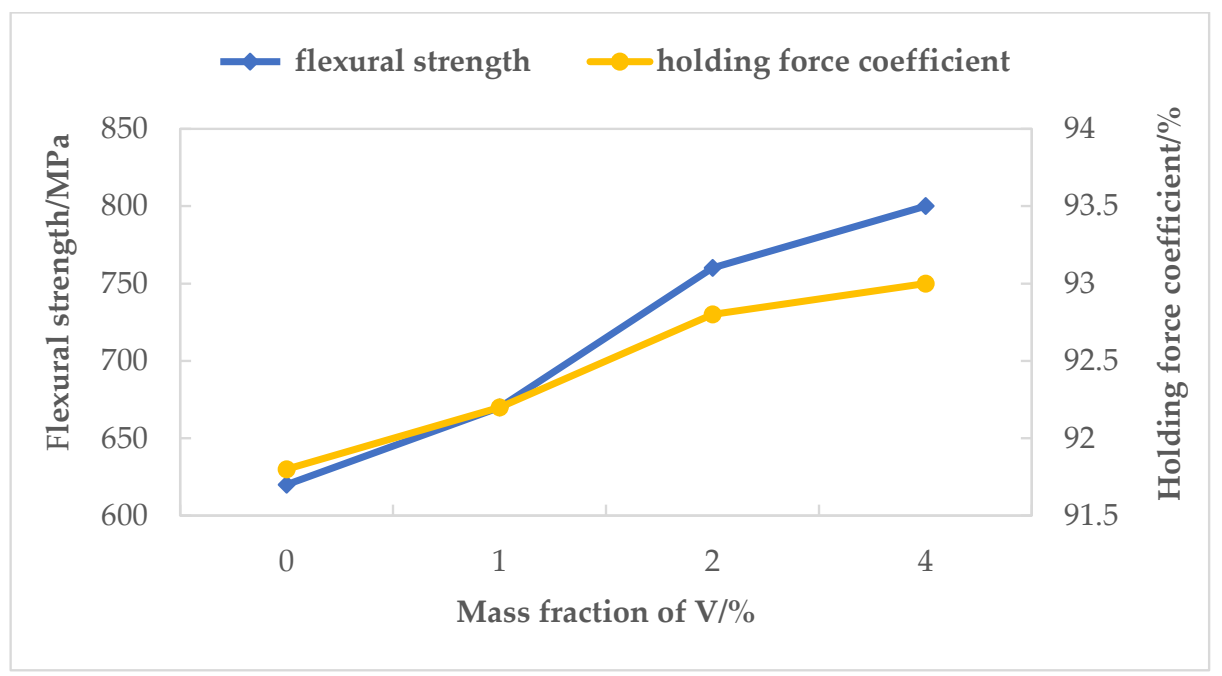

Figure 3. Effects of mass fraction of $\mathrm{V}$ on the flexural strength and the holding force.

However, the approach also has some shortcomings [43]. Firstly, the rate of diamond degradation is relatively high because of the higher reaction temperature between strong carbide forming elements and carbon. The availability of the approach is usually influenced by the contradiction between the enhancement of interfacial bonding strength and the reduction of the strength of the diamond itself. Secondly, the improvement of diamond retention strength is limited, due to the carbon reactivity perhaps not forming a continuous or integral transition layer at the interface between diamond and matrix. Furthermore, the strong carbide forming elements which have usually powerful reducibility may oxidize before reacting with carbon in the production process, thus increasing the difficulty of implementing the technique.

Compared to the method of adding strong carbide forming elements, the method of diamond surface metallization is more common, and undoubtedly, more effective. Both methods have received a lot of attention [44]. First of all, the graphitization on the diamond surface cannot appear under hot pressing or sintering; otherwise, the strong carbide forming elements would directly react with the carbon on the graphitic layers but not the diamond surface, which would cause a significant decrease of bonding strength between diamond and matrix. Secondly, adequate hot-pressing time is required to make strong carbide forming elements fully diffuse to the diamond surface, and then react with carbon. Last but not least, the sintering temperature is needed to chemically react the strong carbide forming elements and carbon.

\subsubsection{Rare Earth Elements}

Rare earth elements, the general term of the lanthanides and the actinides, have many distinct properties. By adding a small quantity of rare earth elements into sintered powder materials, the mechanical properties of diamond composite material can be greatly affected, for example improving the metal structure and interface bonding conditions $[45,46]$.

The active mechanism of rare earth element additives can be concluded as follows. Rare earth elements have high chemical activity, so can react with impurities in the matrix, such as oxygen, sulfur and nitrogen, to suppress the composition segregation, or improve the distribution of impurities [14]. They also play a role in activating sintering, because they deoxidate the metal superficial oxides, thereby reducing the diffusion barrier of atoms through an oxidation film to accelerate the sintering process [47]. Additionally, they can react with impurities on the diamond surface, purifying the 
bonding interface and enhancing the diamond surface activity, which facilitates the chemical reaction between carbide forming elements and the diamond, and improves the interfacial bonding state between diamond and matrix [48]. In addition, the high-melting rare earth compounds have a pinning effect on grain boundaries which is helpful in inhibiting grain growth and refining grains for enhancing the mechanical properties of the matrix [49]. According to [50], the bending strength of the $35 \%$ Fe-based matrix with rare earth Ce increases by $10 \sim 62 \%$ over that of the composites free of rare earth elements (see Figure 4).

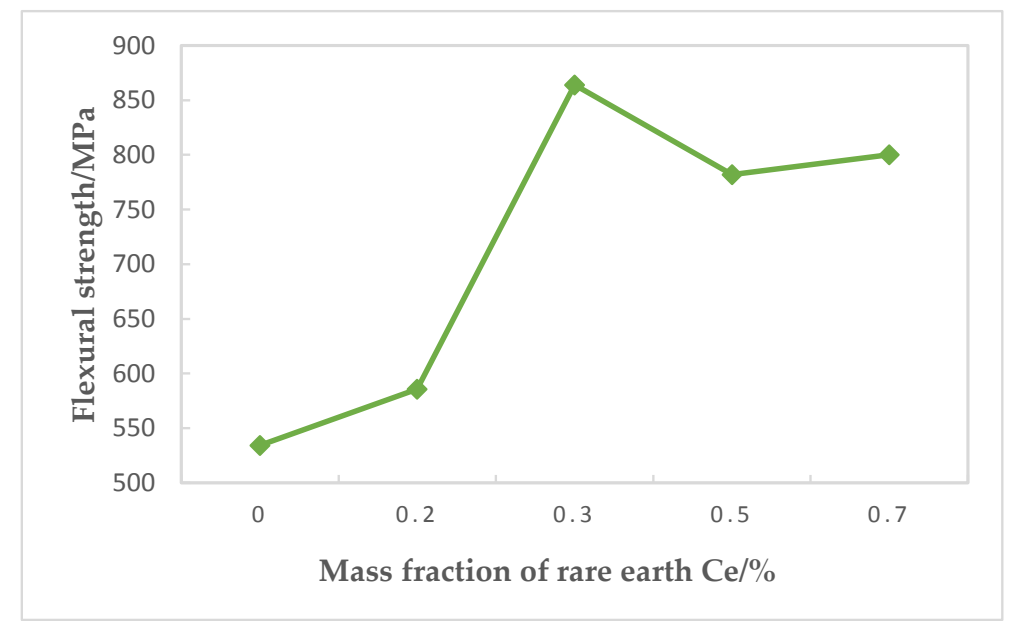

Figure 4. Effect of mass fraction of rare earth Ce on the flexural strength.

\subsubsection{Non-Metallic Elements}

The additions of some non-metallic elements, such as $\mathrm{Si}, \mathrm{P}$, and $\mathrm{B}$, can also play a role in improving the bonding strength between matrix and diamond. Adding a small amount of $\mathrm{Si}$ to the preparation of cobalt-based bonding can enhance the abrasive resistance of the matrix, and lead to an increased adhesion of matrix to the diamond crystals, thus resulting in improved diamond retention [51]. The melting point of copper-based matrix materials can be decreased with the addition of elements $P$ or $\mathrm{B}$, which improves the wetting behavior of $\mathrm{Cu}$ and enhances the interfacial bonding strength $[52,53]$. The addition of element $B$ can decrease the thermal expansion coefficient of diamond reinforced copper composites and strengthen the interfacial bonding [54]. Adding a moderate amount of carbon powder in a high iron-based matrix alloy can promote activated sintering and increase the density and bending strength of the matrix [55].

\subsubsection{Pre-Alloying or Refining of Matrix Powders}

Presently, the design of matrix alloy powder has two development directions, namely pre-alloying and refining. Pre-alloyed powder has some remarkable advantages compared to traditional elemental powder. The elements can form intermetallic compounds and achieve partial or complete mutual dissolution during the preparation of pre-alloyed powder [56]. Component segregation of matrix powder can be avoided, especially when all pre-alloyed powders are consistent with the nominal element composition [57]. By using a matrix pre-alloyed powder, activation energy can be greatly reduced, thus reducing the sintering temperature and time, and avoiding high temperature damage to the diamond [58,59]. On the other hand, the microstructure of the matrix is more uniform (see Figure 5) [60], and the density, hardness and bending strength of the matrix are improved significantly, leading to improvements in bonding strength and the service life of diamond tools [61]. Further, the fixed elementary composition of pre-alloyed powder is convenient to control product quality. The main preparation methods of the pre-alloyed powder for diamond tools are the water atomization method and the hydrometallurgical co-precipitation method. 


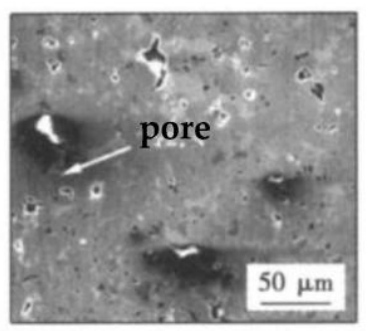

(a) $0 \%$

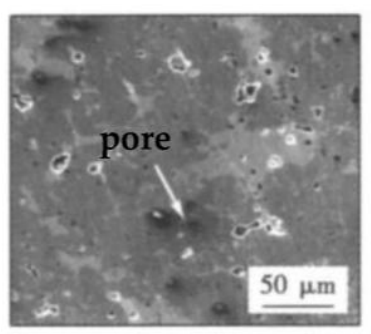

(b) $8 \%$

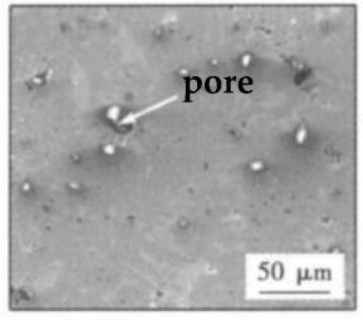

(c) $12 \%$

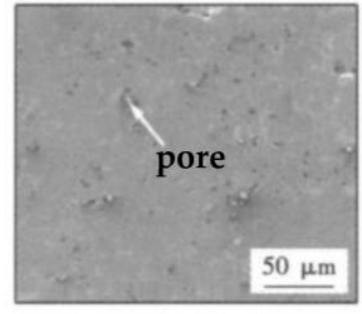

(d) $16 \%$

Figure 5. Microstructures of matrix with different content of pre-alloyed powder.

The addition of superfine powder or nanopowder is another effective way to improve the bonding strength [62,63]. The superfine powder can be used for reducing the sintering temperature and refining the grains which promote the performance of the matrix. The graphitization process of diamond grains in Fe-based composites is suppressed with the addition of WC nanoparticles, and is helpful in improving the adhesion of a binder to diamond grains, and hence the service life of related cutting tools [64]. The chemical activity of nanoparticles is known to be higher than that of bulk material due to better interparticle contact between the components [65]. Additionally, the interaction between the nanoparticles and diamond grains improves the bond properties of diamond tools [66].

\subsection{Changes in Preparation Technology}

Changes in preparation technology include adjusting the sintering process and the application of new technology. The adjustment of the sintering process mainly refers to altering sintering time, temperature, pressure and atmosphere. In comparison, a longer dwelling time at a higher sintering temperature softens the bond by promoting recrystallisation and grain growth in the holding stage, whereas the shorter holding time at a lower sintering temperature may be insufficient to create a perfectly homogenized alloy in the cooling process [67]. Moreover, pressure activates the sintering by inducing creep in the hot pressing; this process is advantageous to protect diamonds against graphitization at low sintering temperatures and short holding times [1]. According to [68], increasing sintering temperature or sintering pressure can improve both the sintering alloying degree and the interfacial reaction between diamond and matrix, which is beneficial to the mechanical properties, as is shown in Table 1.

Table 1. Bending strength of Fe-Based impregnated diamond segments.

\begin{tabular}{cccc}
\hline \multirow{2}{*}{ Mechanical Property } & \multicolumn{3}{c}{ Sintering Process } \\
\cline { 2 - 4 } & $\mathbf{6 8 0}{ }^{\circ} \mathrm{C} / \mathbf{1 5} \mathrm{MPa} / \mathbf{4} \mathbf{~ m i n}$ & $\mathbf{7 6 0}{ }^{\circ} \mathrm{C} / \mathbf{1 5} \mathrm{MPa} / \mathbf{4} \mathbf{m i n}$ & $\mathbf{7 6 0}{ }^{\circ} \mathrm{C} / \mathbf{2 3} \mathbf{~ M P a} / \mathbf{4} \mathbf{~ m i n}$ \\
\hline Bending strength/MPa & 230 & 515 & 700 \\
\hline
\end{tabular}

Graphitization of diamond occurs easily in the presence of a small amount of residual oxygen in the atmosphere surrounding the diamond powder [33]. When the diamond reacts with oxygen, $\mathrm{CO}$ and/or $\mathrm{CO}_{2}$ are common byproducts, leading to the formation of small holes on the surface of the diamond, which cause an increase in specific surface area of the diamond particle, and increasing the rate of graphitization. In order to reduce the rate of graphitization and improve diamond retention, the sintering of composite materials can be performed under protective atmospheres, such as deoxidized or inert atmospheres [69].

In traditional fabrication techniques, the mixture of diamond and matrix is not heated enough to develop a strong chemical bonding between diamond grits to the surrounding matrix, and hence, the product suffers from a lack of retention capacity of diamond particles. The reason lies in the fact that if the mixture is exposed to a sufficiently high temperature to develop a chemical bond between diamond and matrix, the diamond itself will be degraded [70]. To improve diamond 
retention, some new techniques have been developed, such as laser cladding [71,72] and rapid discharge sintering [73], in which the mixture is adequately heated to melt the matrix to develop strong chemical bonding. An advantage of these processes is a short cycle time, thereby minimizing oxidation or graphitization of the diamonds

\subsection{Comparison of Different Improved Techniques}

The enhancing effect and application degree of different improved techniques are summarized in Table 2. Among these improved techniques, diamond surface metallization and pre-alloying or refining of matrix powders have achieved a large-scale industrial application, and have an excellent improvement effect on diamond retention capacity. The additives of strong carbide forming and rare earth elements have many applications, and have a good effect upon the interfacial bonding state between diamond and matrix. As for the techniques of adding non-metallic elements and diamond surface roughening, the enhancing effect and application degree are limited, especially in the case of the surface roughening method mostly used in the field of electroplated diamond tools. The traditional hot-press sintering method is very mature and widespread, and the optimized sintering process is good for improving the bonding strength. In recent years, some new preparation technologies have been developed for forming strong chemical bonding, including laser cladding and rapid discharge sintering, but their application degree is low in diamond tools.

Table 2. Enhancing effect and application degree of different improved techniques.

\begin{tabular}{|c|c|c|c|}
\hline \multicolumn{2}{|c|}{ Improved Techniques } & \multirow{2}{*}{$\begin{array}{c}\text { Enhancing } \\
\text { Effect }\end{array}$} & \multirow{2}{*}{$\begin{array}{c}\begin{array}{c}\text { Application } \\
\text { Degree }\end{array} \\
\text { high } \\
\text { low }\end{array}$} \\
\hline Surface treatment of diamond & $\begin{array}{l}\text { Metallization } \\
\text { Roughening }\end{array}$ & & \\
\hline Modification of the metal matrix & $\begin{array}{c}\text { Strong carbide forming elements } \\
\text { Rare earth elements } \\
\text { Non-metallic elements } \\
\text { Pre-alloying or refining of matrix powders }\end{array}$ & $\begin{array}{l}\text { good } \\
\text { good } \\
\text { limited } \\
\text { excellent }\end{array}$ & $\begin{array}{l}\text { moderate } \\
\text { moderate } \\
\text { low } \\
\text { high }\end{array}$ \\
\hline Change in preparation technology & $\begin{array}{c}\text { Adjustment of sintering process } \\
\text { new technologies (laser cladding, rapid } \\
\text { discharge sintering) }\end{array}$ & $\begin{array}{c}\text { good } \\
\text { excellent }\end{array}$ & $\begin{array}{l}\text { high } \\
\text { low }\end{array}$ \\
\hline
\end{tabular}

\section{Evaluation Methods of Diamond Retention Capacity}

To a large extent, the service life and working efficiency of diamond tools depends on the diamond retention capacity. An insufficient diamond retention capacity usually leads to premature loss of diamond grits, which greatly impacts tools' service lives. On the other hand, an extremely strong diamond retention capacity could retain blunt diamond grits during the working process, thus decreases tools' working efficiencies. It is therefore necessary to evaluate diamond retention capacity. Although the evaluation methods of diamond holding capacity have no uniform specifications or standards, many evaluation means have been adopted and developed by researchers, and can be divided into several categories, including instrument detection, mechanical testing and mechanical calculation.

\subsection{Instrument Detection Methods}

Some instrument detection methods are used to evaluate the diamond retention ability, including SEM, X-ray diffractometry (XRD), energy dispersive spectrometry (EDS), and Raman spectroscopy [71-80]. SEM is mostly utilized to observe the diamond-matrix interfacial morphology of a fractured surface. A good diamond retention can be explained by smooth diamond surfaces, tight contact between diamonds and the matrix, and the existence of a binder on the diamond surfaces. For example, Figure 6 shows that the diamonds have a good wetting behavior to the metal matrix material, which is helpful to form a strong bonding [71]. 


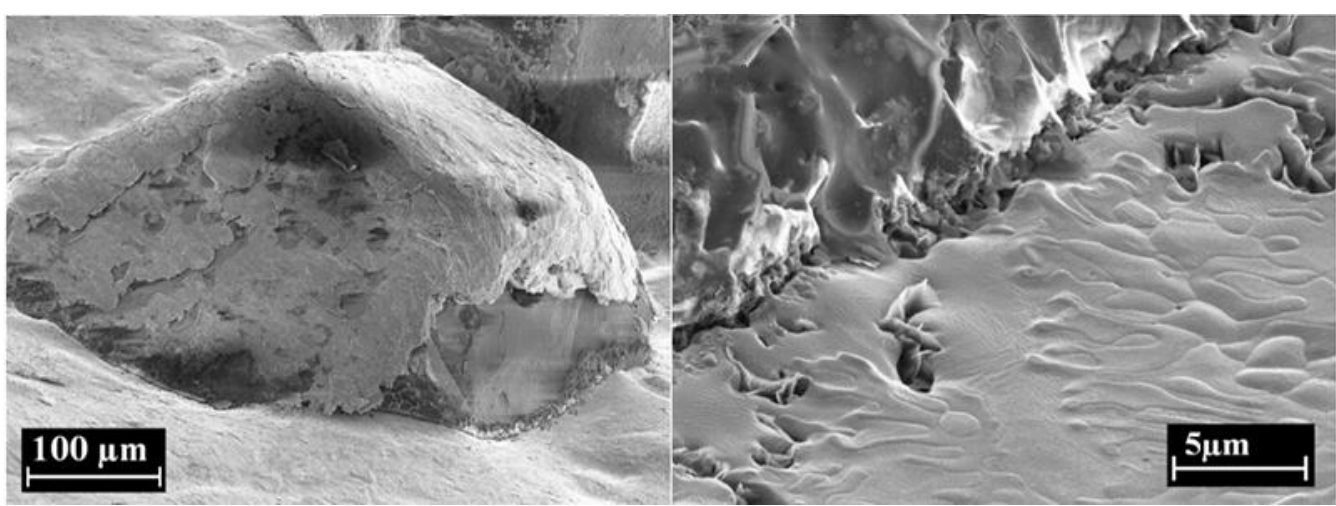

Figure 6. SEM-images of the interface, showing wetting behavior of the diamonds [71], Elsevier, 2016.

XRD and EDS are employed to investigate phase structure and composition, and elemental composition and distribution respectively. The analysis results of XRD or EDS can be used to show the presence of carbides on the diamond surfaces, which could be evidence of the formation of a chemical bond between the matrix and diamonds. For instance, Figure 7 indicates the existence of a tungsten layer, and a chemical combination may occur [35]. Raman spectroscopy can be employed to study diamond graphitization (Figure 8 illustrates the presence of graphite at the surface of brazed diamond [35]) and thermal residual stresses [78-81] which are related to diamond retention ability. The residual stresses $\sigma_{\text {biaxial }}$ can be determined from the shift in the wavenumber $w$ of the Raman-Stokes-peak of a sintered diamond compared to the wavenumber $w_{0}$ of the Raman-Stokes-peak of an unsintered and stress-free diamond according to Equation (1) [81]

$$
\begin{gathered}
\sigma_{\text {biaxial }}=A_{\text {biaxial }} \cdot\left(w-w_{0}\right), \\
A_{\text {biaxial }}=2 \cdot \frac{w_{0}}{\left[p \cdot\left(S_{11}+S_{12}\right)+q \cdot\left(S_{11}+3 \cdot S_{12}\right)\right]}=-0.43 \mathrm{GPa} / \mathrm{cm}^{-1},
\end{gathered}
$$

where $S_{11}$ and $S_{12}$ denote the elastic compliance constants of diamond $\left(S_{11}=1.01 \mathrm{TPa}^{-1}\right.$, $\left.S_{12}=-0.14 \mathrm{TPa}^{-1}\right)$ and $p$ and $q$ are the diamond's phonon deformation potentials $\left(p=-2.82 \cdot w_{0}^{2}\right.$, $\left.q=-1.78 \cdot w_{0}^{2}\right)$.

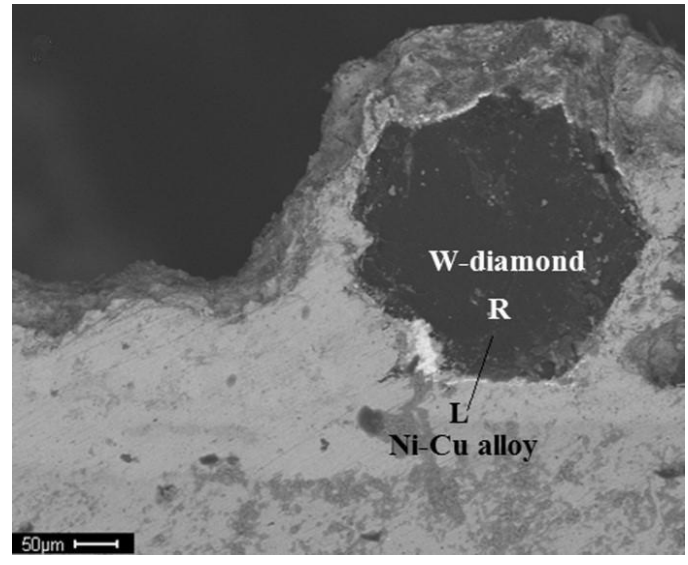

(a)

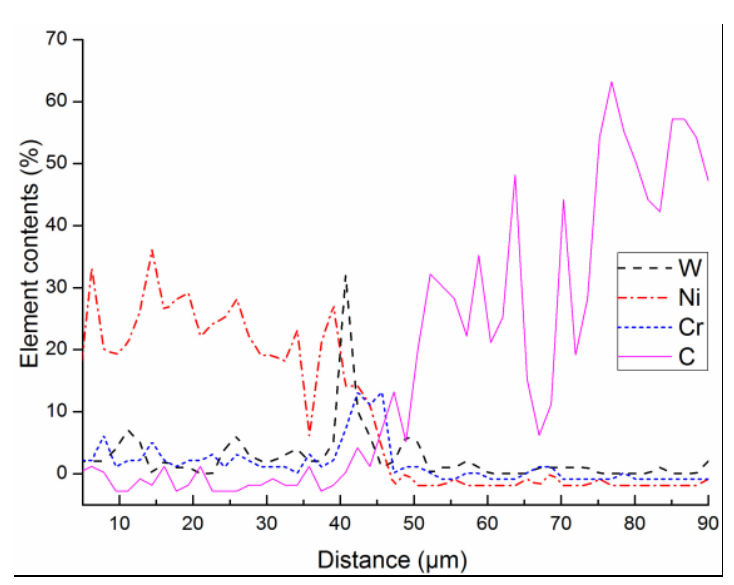

(b)

Figure 7. Backscattered SEM image (a) and corresponding EDS (b) between Ni-Cu alloy and W-coated diamond [35], Taylor \& Francis, 2018. 


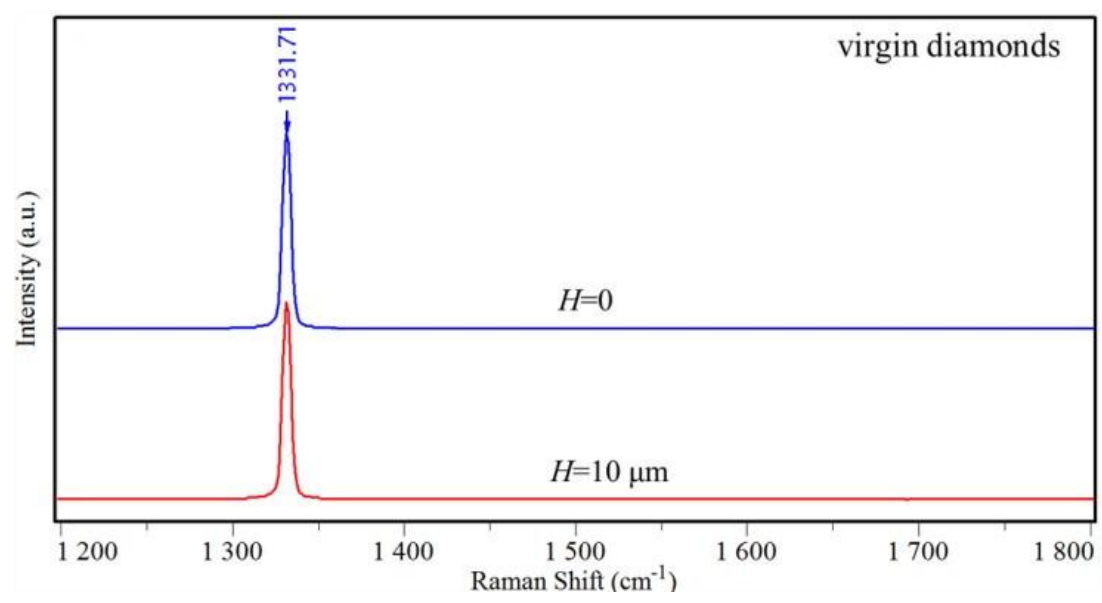

(a) untreated diamond

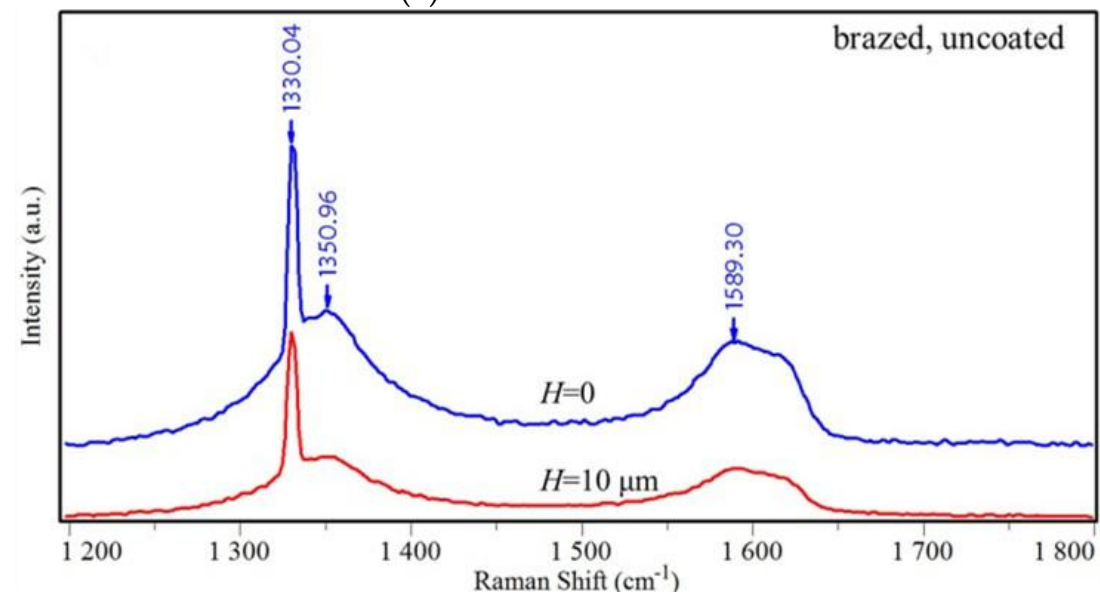

(b) brazed uncoated diamond

Figure 8. Representative Raman spectra of diamonds tested at two depths $(\mathrm{H}=0 \mu \mathrm{m}$ and $\mathrm{H}=10 \mu \mathrm{m})$ [35], Taylor \& Francis, 2018.

\subsection{Mechanical Test Methods}

The mechanical test methods for evaluating diamond retention include the bending strength analytical method, the tension ring test method, and other test methods for chemical bonding strength.

\subsubsection{Bending Strength Analytical Method}

Generally speaking, the bending strength of a diamond segment is governed by the bonding between diamonds and the matrix, as well as the bonding forces among metal matrix particles. Since the bond matrix and sintering conditions are identical for the diamond sintered segments and blank sintered segments, the difference in bending strength should be attributed to a difference in diamond-matrix bonding [30]. Due to the fact that the interface between diamond and matrix is generally the source of fracture, the bending strength of sintered segments with diamond is lower than those with blank. A decreased value for the bending strength can be used to indirectly measure the retention capacity of matrix to diamond. The holding force coefficient $(F)$ is calculated as follows [56,58]:

$$
\begin{gathered}
q=\left(\sigma_{B}-\sigma_{D}\right) / \sigma_{B} \times 100 \%, \\
F=100 \%-q,
\end{gathered}
$$

where $q$ is the decreased bending strength value between diamond sintered segments and blank sintered segments; $\sigma_{B}$ and $\sigma_{D}$ are the bending strength of the blank sintered segments and diamond 
sintered segments respectively; $F$ is the holding force coefficient of matrix to diamond. The greater the holding force coefficient, the stronger the bonding between diamond and matrix. The bending strength for each segment can be determined by using a three-point or four-point bending test.

\subsubsection{Tension Ring Test Method}

Another method based on the tension ring test is also used to evaluate the ability of the matrix in holding diamonds [82]. It can be seen from Figure 9 that the uniformly distributed pressure $P_{1}$ is applied on the inner wall of ring specimen by the function of the load $P$. According to the elastic solution of a thick-walled cylinder based on the elastic-plastic mechanics, the breakage of the ring specimen is caused by the circumferential stress $\sigma_{\theta}$, which has a maximum value at the inner wall of a ring specimen. The bonding strength between diamond and matrix can be characterized by the maximal circumferential stress $\left(\sigma_{\theta \max }\right)$ when the ring specimen is broken. The $\sigma_{\theta \max }$ is calculated as follows:

$$
\begin{gathered}
P_{1}=\frac{(P+M g)(\cos \alpha-f \sin \alpha)}{2 \pi r_{1} h(f \cos \alpha+\sin \alpha)}, \\
\sigma_{\text {max }}=-P_{1} \frac{r_{0}^{2}+r_{1}^{2}}{r_{0}^{2}-r_{1}^{2}}
\end{gathered}
$$

where $P$ is the load applied on the conical rod; $M g$ is the weight of the conical rod; $r_{0}, r_{1}$ and $h$ are the outer diameter, inner diameter and height of the ring specimen, respectively; $\alpha$ is the chamfered angle of the conical rod; and $f$ is the friction coefficient between the conical rod and the load transfer ring.
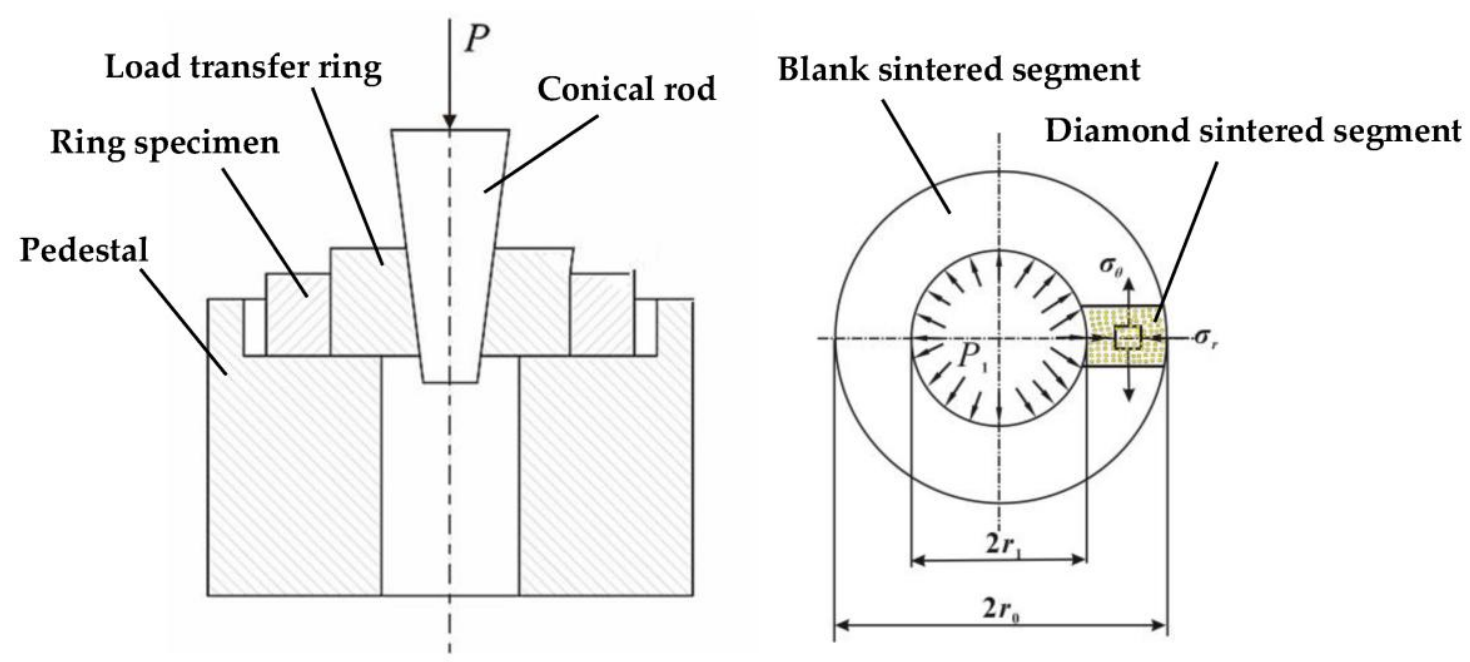

Figure 9. Schematic diagrams of tension ring test and the force conditions of tension ring specimen.

\subsubsection{Test Methods for Chemical Bonding Strength}

Chemical bonding strength can be tested with the normal separation method. A special device (Figure 10) was developed for brazing the test rod to the surface of a diamond crystal, and for carrying out subsequent tests of the separation strength [83]. Prior to brazing, a thin sheet of metal alloy is placed between the end of the rod and the face of the diamond. This method is also suitable for determining the strength of the bond between the diamond and the coating deposited on its surface. In the latter case, the rod must be soldered to the metallized surface of the diamond using any ductile solder which wets the coating well, and has a bond tearing strength that exceeds that of the diamond-metal bond [84]. 


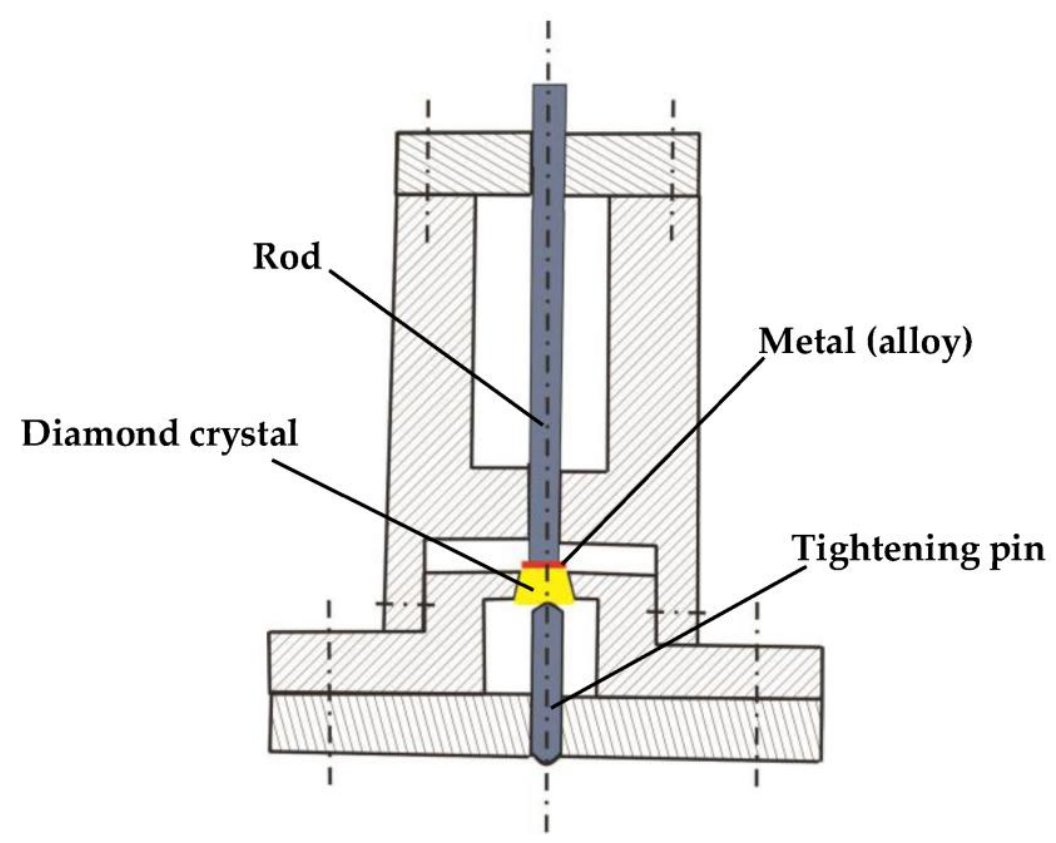

Figure 10. Scheme of the device for determining the strength of the interface between diamond and metal (alloy).

Another method of normal tearing-off is also employed to determine bonding strength. Its essence is that the metal under investigation is melted onto the diamond surface in a special graphite mold (Figure 11). Then the graphite is removed, and the diamond with the solidified fused-on metal is placed in the grips of a rupture-test machine, and tests are conducted [83].

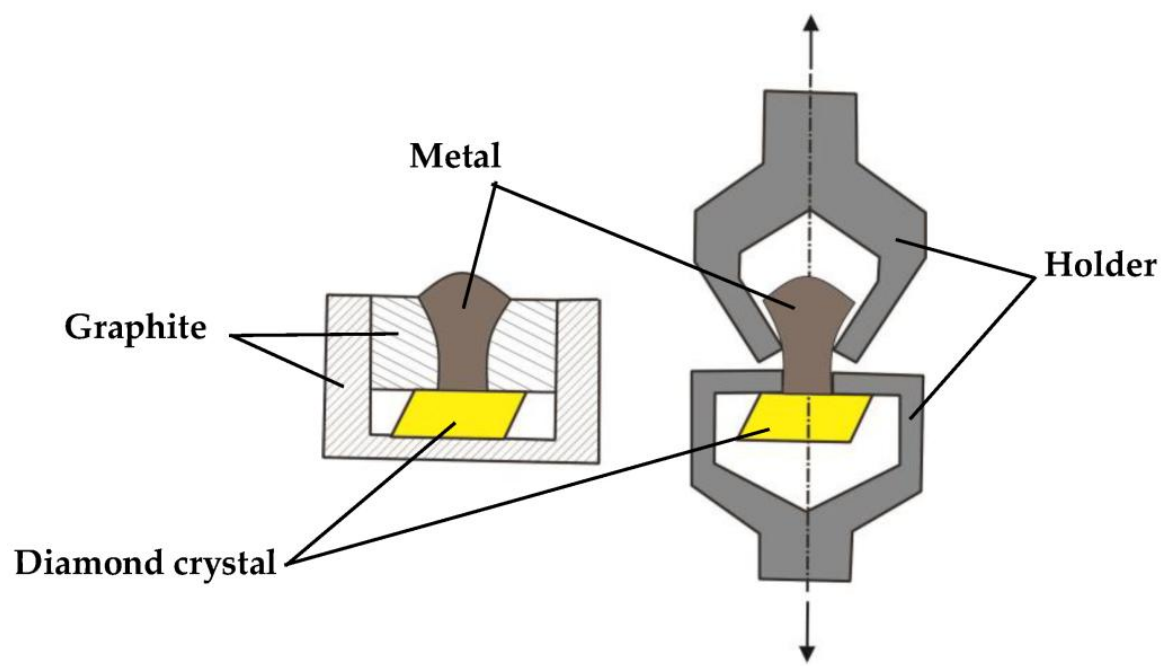

Figure 11. Schemes of melting the metal alloy on a diamond crystal and testing the strength of the diamond-metal interface under tensile loading.

Note that the diamond is under combined stress with predominant tangential forces during tool operation. Therefore, it seems important to study the shear strength of the diamond-metal bond.

An experimental procedure is presented in [85]. A batch of tablets $5 \mathrm{~mm}$ in height was made under a certain pressure from the metal powder. Oval diamond grains 2 to $3 \mathrm{~mm}$ in diameter were soldered to the tablets by copper impregnation in a vacuum furnace (Figure 12). After the specimens were taken out of the furnace and cooled, they were subjected to a shear strength test. 


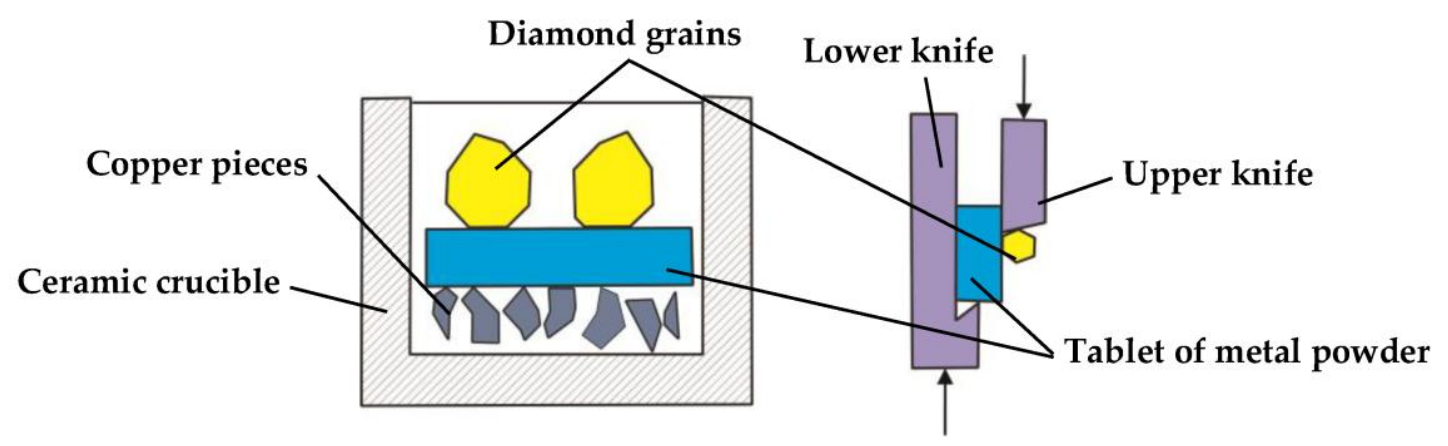

Figure 12. Schemes of soldering of diamond grains to tablets by impregnation and determination of their shear strength of bond.

According to the above methods, the bonding strength is determined as the ratio of the fracture force to the contact spot area, which is measured under a microscope:

$$
\sigma_{\text {fracture }}=\frac{F}{S}
$$

where $\sigma_{\text {fracture }}$ is the diamond-metal bond strength (MPa); $F$ is the fracture force $(\mathrm{N})$; and $S$ is the contact spot area $\left(\mathrm{mm}^{2}\right)$.

Except for the large sized diamond crystal, polycrystalline diamond is also used for bonding strength tests. Typical test methods include the felt-bending test (Figure 13), the compression test (Figure 14), and the tensile test (Figure 15) [86].

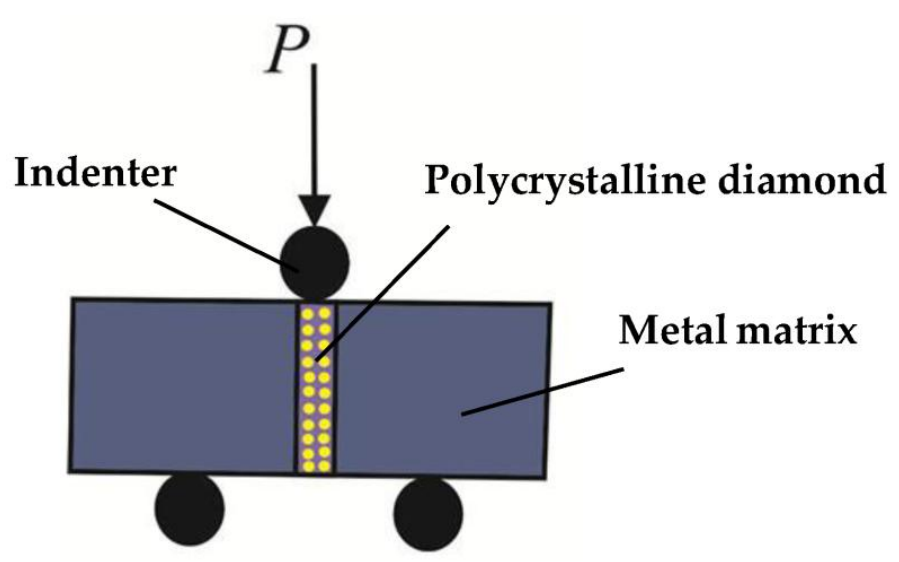

Figure 13. Scheme of felt-bending test method.

\subsection{Mechanical Calculation Methods}

The mechanical calculation methods for evaluating diamond retention consist of two techniques: theoretical calculation and numerical computation.

The maximum mean protrusion height of diamond grains is employed by some researchers to evaluate diamond retention in the diamond tools industry [87-89]. The retention strength is characterized by a constant $\tau$ :

$$
\tau=\frac{h}{d}
$$

where $d$ is the particle size of the diamond; and $h$ is the maximum protrusion height of diamond grains. 
The constant number of diamond per unit area in a diamond tool's working face $N$ is also an indicator of retention strength $\tau:[90]$

$$
\tau=\frac{N \cdot \pi d^{2}}{600 \cdot C},
$$

where $C$ is the diamond concentration (volume fraction).

The residual stress at the interface, which arises from differential thermal expansion between the diamond and matrix material, is a good indicator of mechanical retention capability. According to [91], a composite spherical region consisting of one of the spherical diamonds of radius $a$ at its center surrounded by a concentric shell of matrix material of radius $b$ is considered (Figure 16).

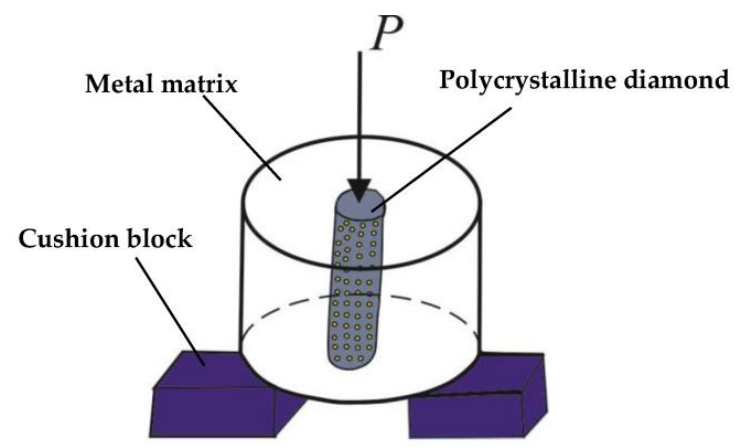

Figure 14. Scheme of compression test method.

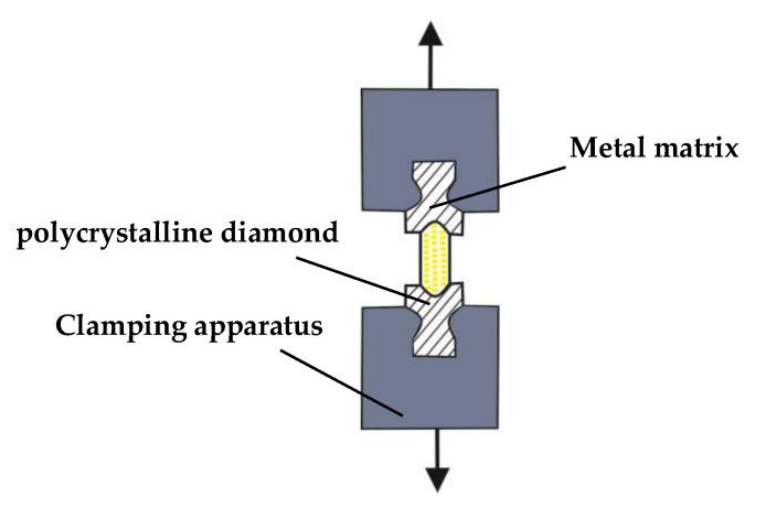

Figure 15. Scheme of tensile test method.

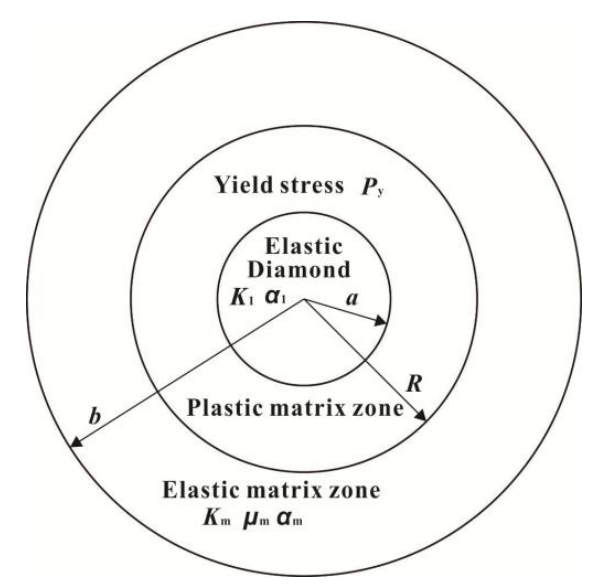

Figure 16. Scheme of simplified model of diamond-matrix. 
Based on the elastic-plastic theory and the von Mises yield criterion, the pressure $P_{a}$ exerted on the diamond surface is given:

$$
\begin{gathered}
\ln \left(\frac{R}{a}\right)^{3}+1-\frac{R^{3}}{b^{3}}+\frac{R^{3}}{4 a^{3}} \frac{K_{1}\left(3 K_{m}+4 \mu_{m}\right)}{\mu_{m}\left(K_{m}-K_{1}\right)}=\frac{9 K_{1} K_{m}\left(\alpha_{m}-\alpha_{1}\right) \Delta T}{2 P_{y}\left(K_{m}-K_{1}\right)}, \\
P_{a}=\frac{2 P_{y}}{3}\left[\ln \left(\frac{R}{a}\right)^{3}+\left(1-\frac{R^{3}}{b^{3}}\right)\right]
\end{gathered}
$$

where $P_{y}$ is the tensile yield stress for the matrix material; $R$ is the radius of the plastic zone; $K_{m}$, $\mu_{m}$ and $\alpha_{m}$ are the bulk modulus, shear modulus and coefficient of thermal expansion of the matrix respectively; $K_{1}$ and $\alpha_{1}$ are the bulk modulus and coefficient of thermal expansion of the diamond, respectively; and $\Delta T$ is the temperature decrease during cooling.

In recent years, numerical computation methods have been widely used to study diamond retention in the matrix, and have been utilized to evaluate thermal residual stresses [92-95], local plastic deformation $[13,96]$ and interfacial pullout behavior $[4,11]$. Cracks are easily generated at the interface due to large thermal stresses; a decrease in thermal residual stress is beneficial to diamond retention strength [29]. The pressure and the elastic energy of a diamond particle and the strain of the deformed matrix around the particle (radius of plastic zone) are good indicators of the efficiency of mechanical retention [97-100]. Diamond retention is estimated by determining the critical force required to pull out the diamond particle from the matrix $[4,11,101]$.

\subsection{Summary on the Evaluation Methods}

Among the above evaluation methods of diamond retention capacity, instrument detection methods are widely used to characterize the matrix and diamond by microstructure analysis to research the related function mechanism, and for qualitative evaluation of the interfacial bonding conditions. The bending strength analytical method is the most common, due to its simplicity and operability; it can indirectly evaluate the retention capacity by the holding force coefficient. The tension ring test method can directly characterize the holding strength by the maximal circumferential stress, but it is rarely used at present because of its lack of practicability, compared to the bending strength analytical method. For the above test methods for chemical bonding strength, there are only a few applications in brazing, and large sized diamond crystal or polycrystalline diamond is used for the bonding strength tests. Mechanical calculation methods, especially numerical simulation method, have been broadly used for evaluating diamond retention capacity for the past few years. However, mechanical calculation methods can only be used to evaluate the mechanical inlaying force, and not to characterize the chemical bonding force.

So far, although many evaluation approaches have been used and developed by researchers, there is still no unified standard or quantitative analysis and evaluation system for determining diamond retention strength.

\section{Conclusions and Discussion}

This article is an investigation of the retention capacity of metal matrix to diamond, mainly involving the constitution, and improved techniques and evaluation methods of diamond retention capacity. Diamond retention capacity can be explained by physical adsorption, mechanical inlay, and chemical bonding at the interface between the diamond and the surrounding matrix. Improved techniques are summarized as three major types: (1) surface treatment of the diamond: metallization and roughening of the diamond surface; (2) modification of metal matrix: the addition of strong carbide forming elements, rare earth elements, and some non-metallic elements, and pre-alloying or refining of matrix powders; (3) change in preparation technology: the adjustment of sintering processes and the application of new technologies. The evaluation methods of diamond retention strength are divided into three categories: (1) instrument detection methods: SEM, 
XRD, EDS and Raman spectroscopy; (2) mechanical test methods: the bending strength analytical method, the tension ring test method, and some other test methods for chemical bonding strength; (3) mechanical calculation methods: theoretical calculation and numerical computation.

Although a large number of studies are available about diamond retention capacity, there are still many problems to be solved in future research. The above-mentioned techniques improve the bonding strength between diamond and matrix to varying degrees, as confirmed by a large number of experiments. But there is still insufficient evidence and conclusions on some function mechanisms, such as the interaction mechanism between diamond and strong carbide forming elements or rare earth elements at the interface. Moreover, no systematic research and comprehensive quantitative evaluation have been conducted so far about the cost, technological complexity, strengthening effect, and performance stability of the improved techniques under practical production conditions, which restricts the broad application of these techniques to a large extent.

Many evaluation approaches have been used and developed, but there is still no unified standard or quantitative analysis and evaluation system for determining diamond retention strength. The systematic quantitative evaluation of diamond retention capacity will undoubtedly be the direction of future study. It is necessary to combine the three categories of evaluation methods of diamond retention strength to establish the calculation models of mechanical inlaying strength, chemical bonding strength and the total retention capacity. Calculation models are related to the mechanical properties of matrix (include elastic modulus, Poisson's ratio, yield strength, thermal expansion coefficient), the diamond parameters (concentration, size, distribution), and the interfacial bonding state (bond types, bond area). A quantitative mathematical relationship is helpful to design and control the holding strength of diamond tools, which can lead to further optimization design of diamond tools' working life and service behavior. This research will be of great significance for carrying out high-speed, high-efficiency and precision machining.

Author Contributions: Xiaojun Zhao planned the content of the paper, conducted the literature research and the majority of the manuscript writing; Longchen Duan participated in the writing and was the instructor and supervisor of the work.

Acknowledgments: This work was supported by the National Natural Science Foundation of China (41672364, 41602373).

Conflicts of Interest: The authors declare no conflict of interest.

\section{References}

1. Artini, C.; Muolo, M.L.; Passerone, A. Diamond-metal interfaces in cutting tools: A review. J. Mater. Sci. 2012, 47, 3252-3264. [CrossRef]

2. Hsieh, Y.; Lin, S. Diamond tool bits with iron alloys as the binding matrices. Mater. Chem. Phys. 2001, 72, 121-125. [CrossRef]

3. De Oliveira, L.J.; da R. Paranhos, R.P.; da S. Guimaraes, R.; Bobrovnitchii, G.S.; Filgueira, M. Use of PM Fe-Cu-SiC composites as bonding matrix for diamond tools. Powder Metall. 2007, 50, 148-152. [CrossRef]

4. Xu, J.; Sheikh, A.H.; Xu, C. 3-D Finite element modelling of diamond pull-out failure in impregnated diamond bits. Diam. Relat. Mater. 2017, 71, 1-12. [CrossRef]

5. Han, P.; Xiao, F.; Zou, W.; Liao, B. Effect of different oxides addition on the thermal expansion coefficients and residual stresses of Fe-based diamond composites. Ceram. Int. 2014, 40, 5007-5013. [CrossRef]

6. Hsieh, Y.Z.; Chen, J.F.; Lin, S.T. Pressureless sintering of metal-bonded diamond particle composite blocks. J. Mater. Sci. 2000, 35, 5383-5387. [CrossRef]

7. Nitkiewicz, Z.; Świerzy, M. Tin influence on diamond-metal matrix hot pressed tools for stone cutting. J. Mater. Process. Technol. 2006, 175, 306-315. [CrossRef]

8. Wang, L.; Guo, S.; Gao, J.; Yang, L.; Hu, T.; Peng, J.; Hou, M.; Jiang, C. Microwave sintering behavior of FeCuCo based metallic powder for diamond alloy tool bit. J. Alloy. Compd. 2017, 727, 94-99. [CrossRef]

9. Reis, L.; Amaral, P.M.; Li, B.; De Freitas, M.; Rosa, L.G. Evaluation of the residual stresses due to the sintering process of diamond-metal matrix hot-pressed tools. Theor. Appl. Fract. Mech. 2008, 49, 226-231. [CrossRef] 
10. Konstanty, J. Production parameters and materials selection of powder metallurgy diamond tools. Powder Metall. 2006, 49, 299-306. [CrossRef]

11. Xu, J.; Sheikh, A.H.; Xu, C. Interfacial failure modelling of diamond bits made of particulate composites. Compos. Struct. 2016, 155, 145-159. [CrossRef]

12. Konstanty, J.; Xu, X. Production of Diamond Sawblades for Stone Sawing Applications. Key Eng. Mater. 2003, 250, 1-12. [CrossRef]

13. Borowiecka-Jamrozek, J.; Lachowski, J. The effect of the properties of the metal matrix on the retention of a diamond particle. Metalurgija 2017, 56, 83-86. Available online: https:/ /hrcak.srce.hr/168891 (accessed on 5 May 2017).

14. Jia, C.C.; Song, Y.Q.; Yu, M.; Wang, T. Effects of rare earth element lanthanum on the microstructure of copper matrix diamond tool materials. Rare Met. 2002, 21, 90-94. Available online: http://apps.webofknowledge.com/full_ record.do?product=UA\&search_mode=GeneralSearch\&qid=1\&SID=5B9PFMeiQIykIPYHLfc\&page=1\&doc=1 (accessed on 22 July 2017).

15. Zeren, M.; Karagöz, Ş. Sintering of polycrystalline diamond cutting tools. Mater. Des. 2007, 28, $1055-1058$. [CrossRef]

16. Li, W.; Zhang, J.; Wang, S.; Dong, H.; Li, Y.; Liu, Y. Characterizations and mechanical properties of impregnated diamond segment using $\mathrm{Cu}-\mathrm{Fe}-\mathrm{Co}$ metal matrix. Rare Met. 2012, 31, 81-87. [CrossRef]

17. Webb, S.W. Diamond retention in sintered cobalt bonds for stone cutting and drilling. Diam. Relat. Mater. 1999, 8, 2043-2052. [CrossRef]

18. De Oliveira, L.J.; Cabral, S.C.; Filgueira, M. Study of the TiC Coating on Powder Metallurgy Diamonds Tool's Performance. Mater. Res. 2015, 18, 441-447. [CrossRef]

19. Song, Y.; Kang, Z.; Gao, Y. Study on Interface of Diamond and Metal Matrix. J. Synth. Cryst. 1999, 28 , 404-408. [CrossRef]

20. Xi, X.; Miao, H.; Zhang, R. Cheng, J. Effect of phosphorus content on the properties of Ni-P coated diamond. Surf. Coat. Technol. 2016, 297, 27-33. [CrossRef]

21. Dwan, J.D. Production of diamond impregnated cutting tools. Powder Metall. 1998, 41, 84-86. [CrossRef]

22. Gu, Q.; Peng, J.; Xu, L.; Srinivasakannan, C.; Zhang, L.; Xia, Y.; Wu, Q.; Xia, H. Preparation of Ti-coated diamond particles by microwave heating. Appl. Surf. Sci. 2016, 390, 909-916. [CrossRef]

23. Tillmann, W.; Ferreira, M.; Steffen, A.; Rüster, K.; Möller, J.; Bieder, S.; Paulus, M.; Tolan, M. Carbon reactivity of binder metals in diamond-metal composites-Characterization by scanning electron microscopy and X-ray diffraction. Diam. Relat. Mater. 2013, 38, 118-123. [CrossRef]

24. Tillmann, W.; Tolan, M.; Lopes-Dias, N.F.; Zimpel, M.; Ferreira, M.; Paulus, M. Influence of chromium as carbide forming doping element on the diamond retention in diamond tools. In Proceedings of the International Conference on Stone and Concrete Machining (ICSCM), Bochum, Germany, 2-3 November 2015; Volume 3, pp. 21-30. [CrossRef]

25. Zhang, C.; Cai, Z.; Wang, R.; Peng, C.; Qiu, K.; Wang, N. Microstructure and thermal properties of $\mathrm{Al} / \mathrm{W}$-coated diamond composites prepared by powder metallurgy. Mater. Des. 2016, 95, 39-47. [CrossRef]

26. Duan, D.; Xiao, B.; Wang, W.; Zhang, Z.; Wang, B.; Han, P.; Ding, X. Interface characteristics and performance of pre-brazed diamond grains with Ni-Cr composite alloy. J. Alloy. Compd. 2015, 644, 626-631. [CrossRef]

27. Ma, B.; Lian, F. Study on the use of CuSnTi brazing alloy for induction brazing of diamond grits surface-treated by direct current plasma chemical vapor deposition. Int. J. Refract. Met. Hard Mater. 2013, 41, 339-344. [CrossRef]

28. Guo, J.; Liu, J.; Hua, C.; Yan, X.; Wei, J.; Chen, L.; Hei, L.; Li, C. Interfacial stress evolution simulation on the graphite substrate/interlayer/diamond film during the cooling process. Diam. Relat. Mater. 2017, 75, 12-17. [CrossRef]

29. Huang, Z.; Xiang, B.; He, Y.; Huang, B. Thermal residual stress analysis of coated diamond grits. Int. J. Miner. Metall. Mater. 2009, 16, 215-219. [CrossRef]

30. Xu, X.; Tie, X.; Wu, H. The effects of a Ti coating on the performance of metal-bonded diamond composites containing rare earth. Int. J. Refract. Met. Hard Mater. 2007, 25, 244-249. [CrossRef]

31. Cabral, S.C.; De Oliveira, L.J.; Filgueira, M. Influence of a TiC Coating on the Wear Resistance of Fe-Diamonds Composites. Mater. Sci. Forum 2012, 727-728, 275-280. [CrossRef]

32. Liu, X.F.; Li, Y.Z. The microanalysis of the bonding condition between coated diamond and matrix. Int. J. Refract. Met. Hard Mater. 2003, 21, 119-123. [CrossRef] 
33. De Oliveira, L.J.; Cabral, S.C.; Filgueira, M. Study hot pressed Fe-diamond composites graphitization. Int. J. Refract. Met. Hard Mater. 2012, 35, 228-234. [CrossRef]

34. Wang, Y.H.; Zang, J.B.; Wang, M.Z.; Guan, Y.; Zheng, Y.Z. Properties and applications of Ti-coated diamond grits. J. Mater. Process. Technol. 2002, 129, 369-372. [CrossRef]

35. Liu, F.; Yang, Y.; Pan, B. Influence of tungsten coating on microstructure and thermal damage of brazed diamonds. Surf. Eng. 2018, 38, 1-8. [CrossRef]

36. Zhang, X.; Guo, H.; Yin, F.; Han, Y.; Fan, Y.; Wang, P. Improving Method of Interface Bonding State in Diamond/Cu Composite Material. Chin. J. Rare Met. 2013, 37, 335-340. [CrossRef]

37. Bai, H.; Dai, D.; Yu, J.H.; Nishimura, K.; Sasaoka, S.; Jiang, N. Architecting boron nanostructure on the diamond particle surface. Appl. Surf. Sci. 2014, 292, 790-794. [CrossRef]

38. Spriano, S.; Chen, Q.; Settineri, L.; Bugliosi, S. Low content and free cobalt matrixes for diamond tools. Wear 2005, 259, 1190-1196. [CrossRef]

39. Zhou, Y.; Zhang, F.; Wang, C. Brazing of diamond by Ag-Cu-Zn alloy with $\mathrm{Cr}$ powder and the microstructure of the interfaces. China Mech. Eng. 2008. [CrossRef]

40. Lin, C.S.; Yang, Y.L.; Lin, S.T. Performances of metal-bond diamond tools in grinding alumina. J. Mater. Process. Technol. 2008, 201, 612-617. [CrossRef]

41. Weizheng, S.I.; Yuan, H.; Zhang, F.L.; Wang, C.Y. Research advances of adding alloying elements in the bond of metal matrix diamond tools. Superhard Mater. Eng. 2007, 35, 33-41. [CrossRef]

42. Wu, Y.; Zhu, Z. Effects of element V on the properties and microstructure of the new copper-matrix bond for diamond tools. J. Yunnan Univ. Natl. (Nat. Sci. Ed.) 2016, 4, 322-324.

43. Xie, Z. Research progress of metal bond of diamond tools. Diam. Abras. Eng. 2006, 153, 71-75. [CrossRef]

44. Dai, Q.L.; Peng, X.X.; Wang, Y.C. Measures Used to Improve Bonding of Diamond to Matrix and Bonding Mechanisms. Mater. Sci. Eng. 2002, 20, 464-468. [CrossRef]

45. Xu, X.P.; Tie, X.R.; Yu, Y.Q. The effects of rare earth on the fracture properties of different metal-diamond composites. J. Mater. Process. Technol. 2007, 187-188, 421-424. [CrossRef]

46. Duan, L.C.; Tang, F.L.; Yang, K.H.; Zou, Q.H. Study of Doping of Rare-Earth Compounds in Iron-Rich Matrix for Diamond Tools. Key Eng. Mater. 2003, 250, 73-77. [CrossRef]

47. Wu, Y.; Li, G. Micromechanism of Rare Earth Alloy Powder in Diamond Tools. Chin. Rare Earths 2007, 28, 60-62. [CrossRef]

48. Dai, Q.L.; Xu, X.; Wang, Y.C. Micro-Analysis of the Use of RE and $\mathrm{TiH}_{2}$ in the Fabrication of Iron-Based Diamond Segments. Key Eng. Mater. 2003, 250, 83-88. [CrossRef]

49. Yu, Y.Q.; Tie, X.R.; Li, Y.; Xu, X. The Effects of Rare Earth on the Hot Pressing of Cu-Sn-TiH $\mathrm{H}_{2}$ Bonded Diamond Composites. Key Eng. Mater. 2006, 315-316, 269-273. [CrossRef]

50. Zhou, Q.; Wang, Z. Experiment on Doping Rare Earth Diamond Tools Matrix Composites with Fe Replacing Co. Appl. Mech. Mater. 2014, 692, 200-205. [CrossRef]

51. De Oliveira, L.J.; Bobrovnitchii, G.S.; Filgueira, M. Processing and characterization of impregnated diamond cutting tools using a ferrous metal matrix. Int. J. Refract. Met. Hard Mater. 2007, 25, 328-335. [CrossRef]

52. Huadong, D.; Yawen, L.; Hongqi, H.; Zhihao, J. Decreasing the sintering temperature of diamond-bit matrix material by the addition of the element P. J. Mater. Process. Technol. 1998, 74, 52-55. [CrossRef]

53. Hsieh, Y.; Lin, S. Interfacial Bonding Strength between Brazing Alloys and CVD Diamond. J. Mater. Eng. Perform. 2009, 18, 312-318. [CrossRef]

54. Fan, Y.M.; Guo, H.; Xu, J.; Chu, K.; Zhu, X.X.; Jia, C.C. Effects of boron on the microstructure and thermal properties of $\mathrm{Cu}$ /diamond composites prepared by pressure infiltration. Int. J. Miner. Metall. Mater. 2011, 18, 472-478. [CrossRef]

55. Han, J.; Yao, J.B.; Ge, Q.L.; Liu, Y.B. Effect of carbon content on performances of high iron-based matrix diamond tools. Mater. Sci. Eng. Powder Metall. 2011, 16, 625-629. [CrossRef]

56. Chu, Z.Q.; Guo, X.Y.; Liu, D.H.; Tan, Y.X.; Li, D.; Tian, Q.H. Application of pre-alloyed powders for diamond tools by ultrahigh pressure water atomization. Trans. Nonferr. Met. Soc. China 2016, 26, 2665-2671. [CrossRef]

57. Xie, Z.G.; Liu, X.Y.; Qin, H.Q.; Wang, J.B.; Jiang, J.F. Sintering and mechanical properties of $\mathrm{FeCoCu}$ fetal body applied for diamond tools. J. Cent. South Univ. 2010, 41, 2178-2183. Available online: http://apps.webofknowledge.com/full_record.do?product=UA\&search_ mode=GeneralSearch\&qid=1\&SID=5CcTL7aFpYoHuOgktpQ\&page=1\&doc=1 (accessed on 9 October 2017). 
58. Xie, D.L.; Wan, L.; Song, D.D.; Wang, S.; Lin, F.; Lü, Z.; Fang, X.H.; Pan, X.Y.; Qin, H.Q.; Chen, C. Effect of composition of $\mathrm{FeCoCu}$ pre-alloyed powders on sintering characters used for diamond tools. Chin. J. Nonferr. Met. 2016, 26, 578-585. [CrossRef]

59. Fang, Y.; Luo, X.; Li, X. Development of pre-alloyed powders for diamond tools and their characteristics. Mater. Sci. Forum 2007, 539-543, 2675-2680. [CrossRef]

60. Ding, T.; Long, W.; Qiao, P.; Pei, Y. Effect and mechanism of pre-alloy powder on microstructure of diamond composite. Trans. China Weld. Inst. 2011, 32, 75-78. Available online: http:/ / www.wanfangdata. com.cn/details /detail.do?_type=perio\&id=hjxb201107019 (accessed on 18 April 2018).

61. Dai, H.; Wang, L.; Zhang, J.; Liu, Y.; Wang, Y.; Wang, L.; Wan, X. Iron based partially pre-alloyed powders as matrix materials for diamond tools. Powder Metall. 2015, 58, 83-86. [CrossRef]

62. Lin, T.; Xiongiian, Y.U.; Shao, H.; Xinbo, H.E.; Wang, Z.; Xiao, S. Effect of the superfine iron-based prealloyed powder on sharpness of diamond disc for cutting granite. J. Funct. Mater. 2015, 21, 21027-21030. [CrossRef]

63. Meiling, J.; Jiapin, C.; Zhiyong, O.; Lina, S.; Haixia, W.; Chun, L. Design \& Application of Diamond Bit to Drilling Hard Rock in Deep Borehole. Procedia Eng. 2014, 73, 134-142. [CrossRef]

64. Sidorenko, D.A.; Zaitsev, A.A.; Kirichenko, A.N.; Levashov, E.A.; Kurbatkina, V.V.; Loginov, P.A.; Rupasov, S.I.; Andreev, V.A. Interaction of diamond grains with nanosized alloying agents in metal-matrix composites as studied by Raman spectroscopy. Diam. Relat. Mater. 2013, 38, 59-62. [CrossRef]

65. Levashov, E.; Kurbatkina, V.; Alexandr, Z. Improved Mechanical and Tribological Properties of Metal-Matrix Composites Dispersion-Strengthened by Nanoparticles. Materials 2010, 3, 97-109. [CrossRef]

66. Zaitsev, A.A.; Sidorenko, D.A.; Levashov, E.A.; Kurbatkina, V.V.; Andreev, V.A.; Rupasov, S.I.; Sevast Yanov, P.V. Diamond tools in metal bonds dispersion-strengthened with nanosized particles for cutting highly reinforced concrete. J. Superhard Mater. 2010, 32, 423-431. [CrossRef]

67. Han, P.; Xiao, F.; Zou, W.; Liao, B. Influence of hot pressing temperature on the microstructure and mechanical properties of 75\% Cu-25\% Sn alloy. Mater. Des. 2014, 53, 38-42. [CrossRef]

68. Dong, H.F.; Yang, L.U.; Wen-Sheng, L.I.; Jie, Z.; Ke, C. Structure and tribological properties of Fe-based impregnated diamond abrasive-head prepared by different sintering technology. Mater. Sci. Eng. Powder Metall. 2013, 18, 125-131. [CrossRef]

69. Mancisidor, A.; Luno-Bilbao, C.; Vielma, N.J.; Sanchez, J.M.; Iturriza, I. Effect of sintering atmosphere on densification, mechanical properties and diamond stability of prealloyed diamond impregnated composites obtained by free sintering. Powder Metall. 2013, 56, 362-373. [CrossRef]

70. Iravani, M.; Khajepour, A.; Corbin, S.; Esmaeili, S. Pre-placed laser cladding of metal matrix diamond composite on mild steel. Surf. Coat. Technol. 2012, 206, 2089-2097. [CrossRef]

71. Rommel, D.; Scherm, F.; Kuttner, C.; Glatzel, U. Laser cladding of diamond tools: Interfacial reactions of diamond and molten metal. Surf. Coat. Technol. 2016, 291, 62-69. [CrossRef]

72. Rommel, D.; Terock, M.; Scherm, F.; Kuttner, C.; Glatzel, U. Direct metal deposition of abrasive tracks-Potentials concerning geometry and materials. J. Laser Appl. 2017, 29, 002508. [CrossRef]

73. Twomey, B.; Breen, A.; Byrne, G.; Hynes, A.; Dowling, D.P. Rapid discharge sintering of nickel-diamond metal matrix composites. J. Mater. Process. Technol. 2011, 211, 1210-1216. [CrossRef]

74. Chou, C.; Lee, J.; Chen, Y. Tribological and mechanical properties of HFCVD diamond-coated WC-Co substrates with different Cr interlayers. Surf. Coat. Technol. 2008, 203, 704-708. [CrossRef]

75. Reichert, F.; Pérez-Mas, A.M.; Barreda, D.; Blanco, C.; Santamaria, R.; Kuttner, C.; Fery, A.; Langhof, N.; Krenkel, W. Influence of the carbonization temperature on the mechanical properties of thermoplastic polymer derived C/C-SiC composites. J. Eur. Ceram. Soc. 2017, 37, 523-529. [CrossRef]

76. Ciupiński, Ł.; Kruszewski, M.J.; Grzonka, J.; Chmielewski, M.; Zielińsk, R.; Moszczyńska, D.; Michalski, A. Design of interfacial $\mathrm{Cr}_{3} \mathrm{C}_{2}$ carbide layer via optimization of sintering parameters used to fabricate copper/diamond composites for thermal management applications. Mater. Des. 2017, 120, $170-185$. [CrossRef]

77. Dong, H.F.; Guo, C.S. Interfacial properties of Fe-Cu based diamond composite ultra thin saw blade. Mater. Sci. Eng. Powder Metall. 2015, 20, 213-217. [CrossRef]

78. Lu, J.; Xu, J. Interface Microstructure and Thermal Stress of Diamond Brazing with Ag-Cu-Ti Filler. Rare Met. Mater. Eng. 2009, 38, 642-646. [CrossRef]

79. Qiu, W.Q.; Dasari, A.; Mai, Y.W. Improvement in adhesion of diamond film on Cu substrate with an inlay structured interlayer. Surf. Coat. Technol. 2011, 206, 224-227. [CrossRef] 
80. Chen, S.; Shen, B.; Zhang, J.; Wang, L.; Sun, F. Evaluation on residual stresses of silicon-doped CVD diamond films using X-ray diffraction and Raman spectroscopy. Trans. Nonferr. Met. Soc. China 2012, 22, 3021-3026. [CrossRef]

81. Buhl, S.; Leinenbach, C.; Spolenak, R.; Wegener, K. Microstructure, residual stresses and shear strength of diamond-steel-joints brazed with a Cu-Sn-based active filler alloy. Int. J. Refract. Met. Hard Mater. 2012, 30, 16-24. [CrossRef]

82. Yuan, G. On Increasing the Diamond-setting Ability of Bit Matrix. Geol. Prospect. 1989, 25, 51-55. Available online: http:/ / www.wanfangdata.com.cn/details / detail.do?_type=perio\&id=QK000000366897 (accessed on 21 June 2017).

83. Naidich, Y.V.; Umanskii, V.P.; Lavrinenko, I.A. Strength of the Diamond-Metal Interface and Brazing of Diamonds; Cambridge International Science Publishing: Cambridge, UK, 2007.

84. Konovalenko, T.B.; Umanskii, V.P.; Evdokimov, V.A.; Bugaev, A.A. Choice of method for the determination of the strength of diamond fastening in the drilling tool matrix. Strength Mater. 2007, 39, 671-676. [CrossRef]

85. Unianskii, V.P.; Konovalenko, T.B.; Evdokimov, V.A.; Bugaev, A.A. Effect of chromium and binder on diamond-matrix contact strength. Powder Metall. Met. Ceram. 2007, 46, 513-516. [CrossRef]

86. Guo, Z.M.; Song, Y.Q. Superhard Materials and Tools; Metallurgy Industry Press: Beijing, China, 1996.

87. Yu, Y.Q.; Tie, X.R.; Zhang, G.Q.; Huang, G.Q.; Huang, H.; Xu, X.P. Comparison of brazed and sintered diamond tools for grinding of stone. Mater. Res. Innov. 2014, 182, 869-873. [CrossRef]

88. Zhang, S.; Wen, T.; Liu, Z. Quantitative relation between performance of diamond saw blade and formulation parameters of its bits. Powder Metall. Technol. 2004, 22, 19-21. [CrossRef]

89. Zhang, S.H. Research on Quantitative Relationship between Property of Diamond Sawblade and Formula Parameters of Segment. Key Eng. Mater. 2004, 259-260, 159-164. [CrossRef]

90. Zhang, S.H.; Yang, K.H.; Lu, F. Research into Bit for Extra-Hard Rock. Key Eng. Mater. 2001, 202-203, 485. [CrossRef]

91. Bullough, R.; Davis, L.C. The residual deformation fields in particle reinforced metal-matrix composites. Acta Metall. Mater. 1995, 43, 2737-2742. [CrossRef]

92. Yakhutlov, M.M.; Karamurzov, B.S.; Batyrov, U.D.; Oshkhunov, M.M.; Kardanova, M.R. Stress-strain state in the grit-matrix system of a diamond tool under force disturbances. J. Superhard Mater. 2009, 31, 418-424. [CrossRef]

93. Yakhutlov, M.M.; Karamurzov, B.S.; Batyrov, U.D.; Berov, Z.Z.; Kardanova, M.R. Thermal conditions and stress-strain state in the grain-matrix system of diamond tools. J. Superhard Mater. 2011, 33, 352-361. [CrossRef]

94. Reis, L.G.; Amaral, P.M.; Li, B.; Anjinho, C.A.; Rosa, L.G. Finite Element Analysis of the Thermal Residual Stresses of Diamond Cutting Tools in the Sintering Process. Mater. Sci. Forum 2008, 587-588, 695-699. [CrossRef]

95. Borowiecka-Jamrozek, J.; Lachowski, J. Numerical Modelling of Stress/Strain Field Arising in Diamond-Impregnated Cobalt. Arch. Metall. Mater. 2014, 59. [CrossRef]

96. Li, B.; Amaral, P.M.; Reis, L.; Anjinho, C.A.; Rosa, L.G.; Freitas, M.D. 3D-modelling of the local plastic deformation and residual stresses of PM diamond-metal matrix composites. Comput. Mater. Sci. 2010, 47, 1023-1030. [CrossRef]

97. Romański, A. Factors Affecting Diamond Retention in Powder Metallurgy Diamond Tools. Arch. Metall. Mater. 2010, 55. [CrossRef]

98. Borowiecka-Jamrozek, J.; Lachowski, J. Modelling of the Mechanical State of a Diamond Particle in the Metallic Matrix. Adv. Mater. Res. 2014, 874, 127-132. [CrossRef]

99. Borowiecka-Jamrozek, J.; Lachowski, J. Modelling of Retention of a Diamond Particle in Matrices Based on Fe and Cu. Procedia Eng. 2017, 177, 289-296. [CrossRef] 
100. Borowiecka-Jamrozek, J.; Lachowski, J. An Analysis of the Retention of a Diamond Particle in a Metallic Matrix after Hot Pressing. Arch. Foundry Eng. 2017, 17, 17-20. [CrossRef]

101. Romanski, A.; Lachowski, J. Effect of friction coefficient on diamond retention capabilities in diamond impregnated tools. Arch. Metall. Mater. 2009, 54, 1111-1118. Available online: http://www.researchgate. net/publication/275956611_Effect_of_friction_coefficient_on_diamond_retention_capabilities_in_diamond_ impregnated_tools\% (accessed on 25 October 2017).

(c)

(C) 2018 by the authors. Licensee MDPI, Basel, Switzerland. This article is an open access article distributed under the terms and conditions of the Creative Commons Attribution (CC BY) license (http://creativecommons.org/licenses/by/4.0/). 